ПРИХОДЬКО С. І., д.т.н., професор,

ШТОМПЕЛЬ М. А., д.т.н., доцент,

ЖУЧЕНКО О. С., к.Т.н., доцент,

ЛИСЕЧКО В. П., к.Т.Н., доценТ,

ШУВАЛОВА Ю.С., к.ф.-м.н., доцент (Український державний університет залізничного транспорту)

\title{
Дослідження ефективності адаптивного методу декодування алгебраїчних згорткових кодів перемежування
}

Розроблено математичну модель телекомунікаційної системи, щзо дозволяє оцінити ефективність методів декодування алгебраїчних згорткових кодів перемежування у каналі зв'язку з групуванням помилок. Подано схему та призначення основних елементів даної математичної моделі, а також визначено особливості їі програмної реалізації. Показано, щчо для моделі каналу зв'язку з релеївським розсіюванням адаптивний метод декодування даних кодів забезпечує більший енергетичний виграш від кодування, ніж алгебраӥчний метод декодування.

Ключові слова: згорткові коди, перемежування, адаптивне декодування, ефективність, телекомунікаційні системи.

\begin{abstract}
Постановка проблеми та аналіз літератури
При побудові сучасних телекомунікаційних систем різного призначення широкого застосування набувають згорткові коди. Важливим класом даних кодів $\epsilon$ алгебраїчні коди, що характеризуються високими конструктивними характеристиками. У [1 3] подано підходи до синтезу алгебраїчних згорткових кодів для каналів зв'язку з випадковими помилками. Для передавання інформації у каналах зв'язку 3 групуванням помилок запропонована модифікація даних кодів 3 використанням принципу перемежування [4, 5]. Основними методами декодування алгебраїчних згорткових кодів перемежування $\epsilon$ жорстке декодування на основі алгебраїчного підходу [6] та м'яке адаптивне декодування на основі спільного використання біоінспірованих процедур та адаптивного розповсюдження довіри [7]. Слід зазначити, що через постійне зростання вимог до достовірності передавання інформації у телекомунікаційних системах підвищується роль саме м'якого декодування даних кодових конструкцій.
\end{abstract}

Тому актуальним завданням $є$ розгляд питань, що стосуються оцінки ефективності адаптивного методу декодування алгебраїчних згорткових кодів перемежування.

\begin{tabular}{llllr}
\hline Мета статті & & & \\
\hline \multicolumn{1}{c}{ Визначення } & характеристик & адаптивного методу \\
декодування & алгебраїчних & згорткових & кодів \\
перемежування & у каналах & зв’язку 3 & групуванням \\
помилок для & забезпечення & його & ефективного \\
застосування & у сучасних & телекомунікаційних
\end{tabular}

системах.

\section{Основна частина}

Загальний підхід до адаптивного декодування алгебраїчних згорткових кодів перемежування подано у [7]. У даній роботі показано, що кожна ітерація декодування містить стадію декодування на основі узагальнених біоінспірованих процедур та стадію декодування на основі процедур адаптивного розповсюдження довіри. Ключові принципи та особливості технічної реалізації даних стадій декодування наведено у [8].

Для оцінки ефективності адаптивного методу декодування алгебраїчних згорткових кодів перемежування пропонується розроблена математична модель телекомунікаційної системи. Дана модель враховує особливості передавання інформації 3 використанням цього виду завадостійкого кодування в залежності від характеристик завадової обстановки. Розроблена модель передбачає використання заданого алгебраїчного згорткового коду перемежування спільно з адаптивним методом декодування для моделі каналу зв'язку 3 релеївським розсіюванням (канал Релея). При цьому існує можливість змінювати 
параметри алгебраїчних згорткових кодів перемежування, характеристики завад у каналі зв'язку та здійснити порівняння адаптивного методу 3 існуючим алгебраїчним методом декодування.

Створення даної моделі телекомунікаційної системи засновано на програмній реалізації алгоритму та псевдокоду адаптивного декодування алгебраїчних згорткових кодів перемежування, заданих узагальненим модифікованим породжувальним багаточленом, що подано у [8].

Схему розробленої математичної моделі телекомунікаційної системи, що дозволяє дослідити властивості адаптивного методу декодування алгебраїчних згорткових кодів перемежування, подано на рис. 1.

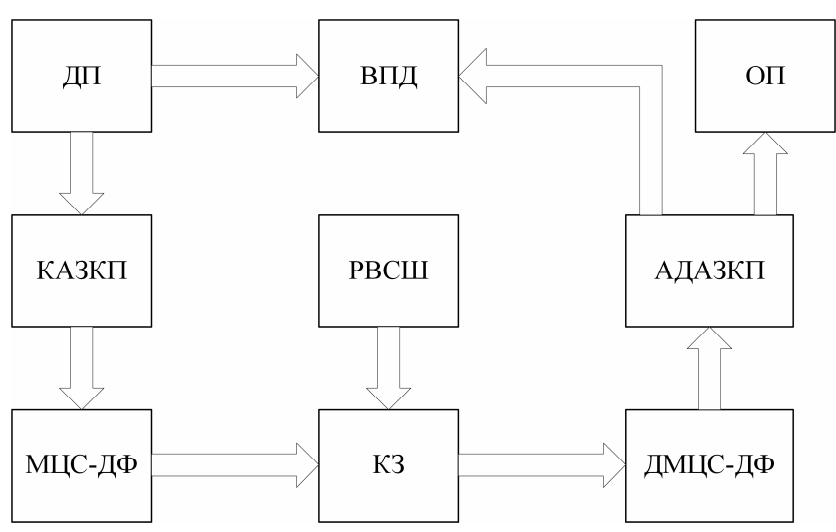

Рис. 1. Схема математичної моделі телекомунікаційної системи з кодером алгебраїчних згорткових кодів перемежування та адаптивним декодером

Джерело повідомлень (ДП) формує псевдовипадкову інформаційну послідовність 3 рівномірним розподілом ймовірностей. Після цього кодер алгебраїчного згорткового коду перемежування (КАЗКП) здійснює іï перетворення у кодову послідовність, що визначається узагальненим модифікованим породжувальним багаточленом 3 обраною глибиною перемежування та іншими параметрами кодової конструкції. Крім того інформаційна послідовність надходить на вимірювач помилок декодування (ВПД) для визначення коефіцієнта (ймовірності) помилок декодування.

В подальшому за допомогою модулятора цифрового сигналу на основі двійкової фазової модуляції (МЦС-ДФ) відбувається перетворення кодової послідовності у фазомодульований сигнал. Сформований сигнал передається по каналу зв'язку (К3), характеристики якого відповідають моделі каналу зв'язку з релеївським розсіюванням. При цьому регулятор відношення сигнал/шум (РВСШ) дозволяє змінювати відношення сигнал/шум у заданому діапазоні. Сигнал $з$ каналу надходить на демодулятор двійкового фазомодульованого цифрового сигналу (ДМЦС-ДФ), що перетворює його у прийнятий вектор, який подається на вхід адаптивного декодера алгебраїчного згорткового коду перемежування (АДАЗКП), що реалізує алгоритм м'якого декодування 3 використанням обраної біоінспірованої процедури 3 заданими параметрами [7].

У результаті декодування АДАЗКП формує оцінку переданої кодової послідовності та відповідну інформаційну послідовність, що передається на отримувач повідомлення (ОП) та на вхід ВПД, що дозволяє оцінити ефективність декодування алгебраїчного згорткового коду перемежування для заданих умов передавання інформації. Після цього відбувається візуалізація отриманих у ході експерименту даних у відповідні графіки залежності коефіцієнта помилок декодування від відношення сигнал/шум. Для оцінки ефективності адаптивного методу декодування алгебраїчних згорткових кодів перемежування також було здійснено реалізацію існуючого алгебраїчного методу декодування, особливості якого наведено у [6].

При програмній реалізації розробленої математичної моделі телекомунікаційної системи використовувались такі настроювання:

1) тип коду - алгебраїчний згортковий код перемежування;

2) параметри коду - довжина кадру кодової послідовності, довжина інформаційного кадру, довжина кодового обмеження, глибина перемежування;

3) діапазон відношення сигнал/шум - від 0 до 18 дБ;

4) кількість інформаційних повідомлень (кодових послідовностей згорткової кодової конструкції), що будуть передаватися, - 1000;

5) параметри адаптивного методу декодування, заснованого на процедурі диференційної еволюції [9] максимальна кількість ітерацій $L_{\max }=100$, розмір популяції $N P=20, \quad$ коефіцієнт впливу $a=0,7$, імовірність «схрещення» $b=0,9$.

На рис. 2 - 4 подано порівняння результатів моделювання у каналі Релея адаптивного методу декодування та алгебраїчного методу декодування для алгебраїчних згорткових кодів перемежування 3 обраними параметрами.

3 аналізу рис. 2 слідує, що поданий метод декодування у порівнянні 3 алгебраїчним методом декодування забезпечує енергетичний виграш від кодування 5,9 дБ при коефіцієнті помилок $10^{-2} ; 5,8$ дБ при коефіцієнті помилок $10^{-3} ; 6,5$ дБ при коефіцієнті помилок $10^{-4}$.

3 графіків на рис. 3 випливає, що розроблений метод декодування у порівнянні 3 алгебраїчним методом декодування забезпечує енергетичний виграш 
від кодування 4,6 дБ при коефіцієнті помилок $10^{-2}$; коефіцієнті помилок $10^{-4}$. 5,5 дБ при коефіцієнті помилок $10^{-3} ; 6,2$ дБ при

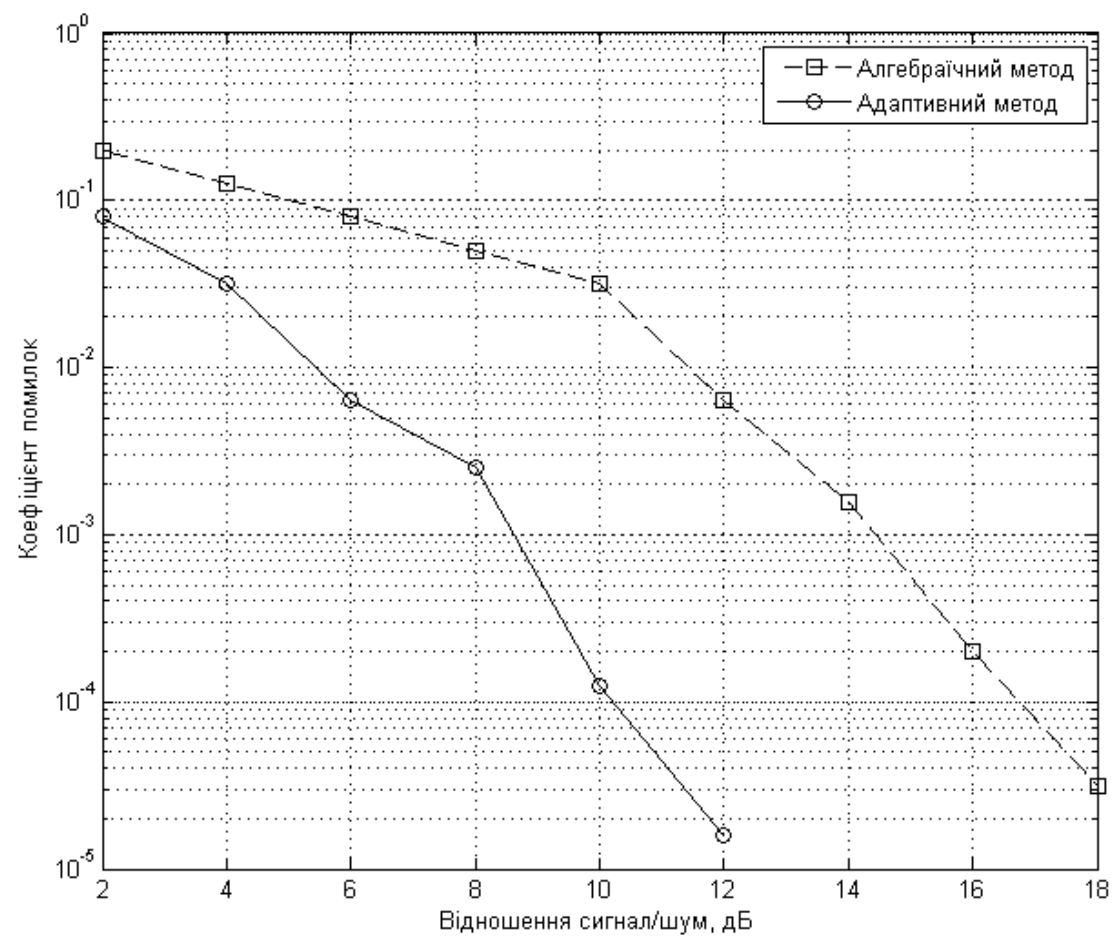

Рис. 2. Залежність коефіцієнта помилок від відношення сигнал/шум для алгебраїчного $(4,1,8,15)$ згорткового коду перемежування

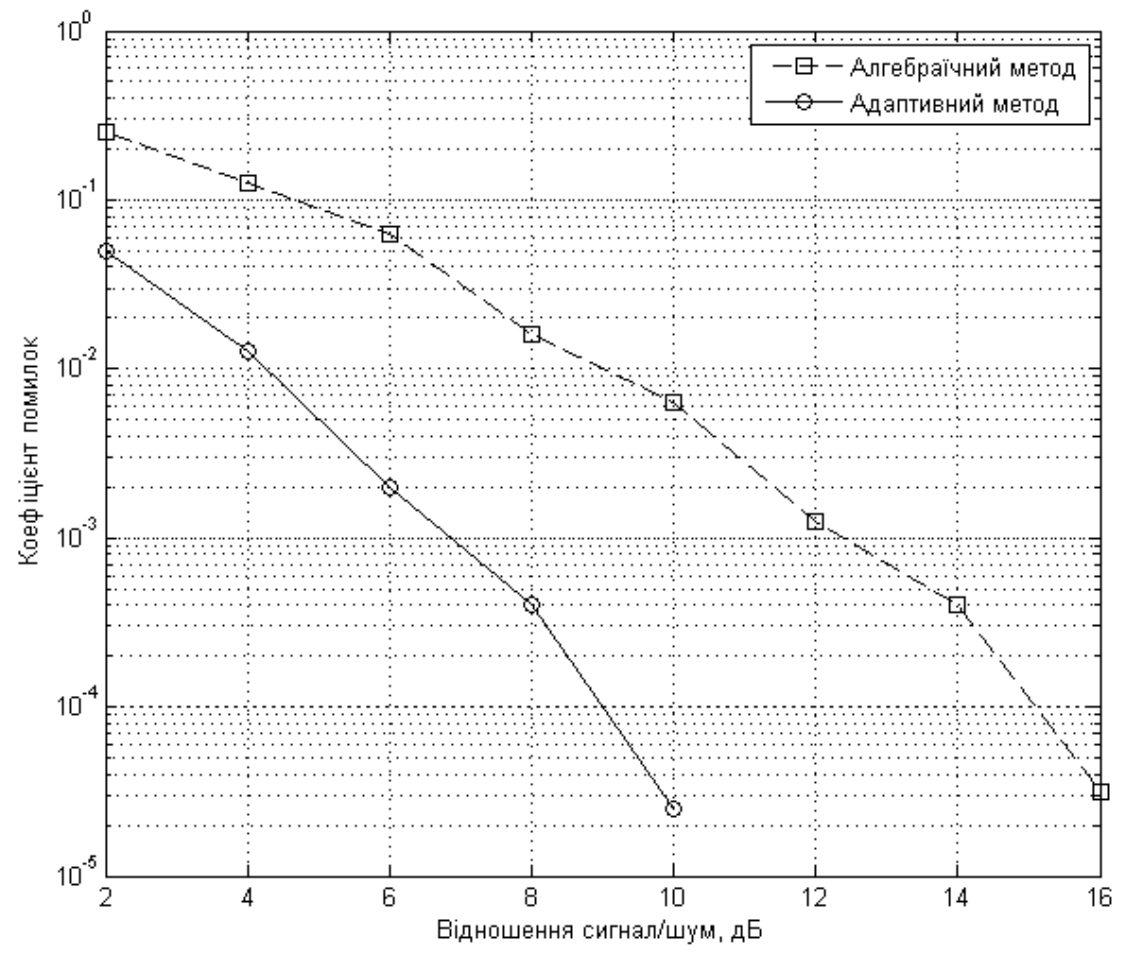

Рис. 3. Залежність коефіцієнта помилок від відношення сигнал/шум для алгебраїчного $(5,1,16,31)$ згорткового коду перемежування 


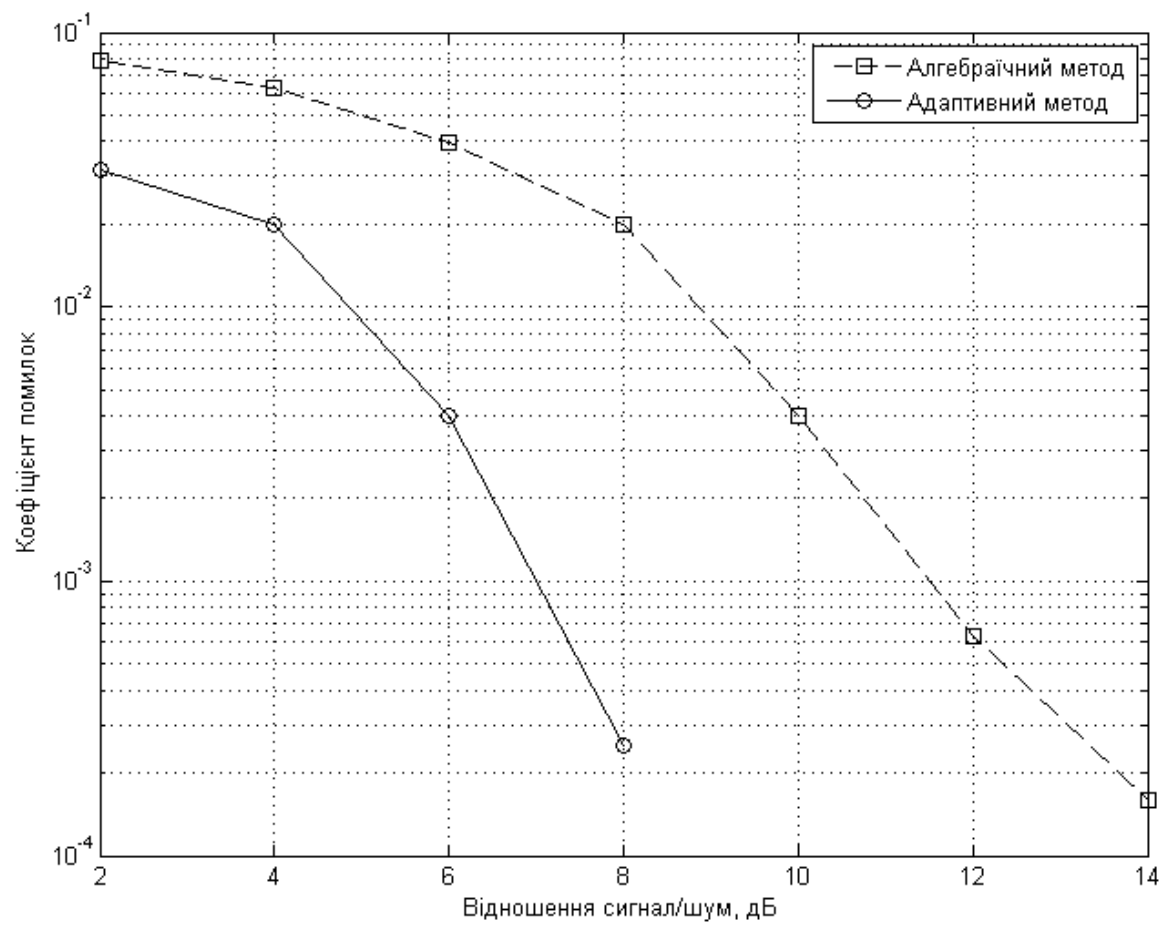

Рис. 4. Залежність коефіцієнта помилок від відношення сигнал/шум для алгебраїчного $(6,1,32,63)$ згорткового коду перемежування

Аналіз рис. 4 показує, що адаптивний метод декодування даного алгебраїчного згорткового коду перемежування у порівнянні з алгебраїчним методом декодування забезпечує енергетичний виграш від кодування 4,1 дБ при коефіцієнті помилок $10^{-2} ; 4,6$ дБ при коефіцієнті помилок $10^{-3}$.
Числові результати, що отримані у ході проведених експериментальних досліджень, для алгебраїчних згорткових кодів перемежування 3 обраними параметрами у заданому діапазоні коефіцієнта помилок наведено у таблиці 1.

Таблиця 1

\section{Результати моделювання для алгебраїчних згорткових кодів перемежування}

\begin{tabular}{|c|c|c|c|c|}
\hline $\begin{array}{c}\text { Параметри коду (довжина кадру } \\
\text { кодової послідовності, довжина } \\
\text { інформаційного кадру, довжина } \\
\text { кодового обмеження, глибина } \\
\text { перемежування) }\end{array}$ & $\begin{array}{c}\text { Коефіцієнт } \\
\text { помилок }\end{array}$ & $\begin{array}{c}\text { Відношення } \\
\text { сигнал/шум при } \\
\text { алгебраїчному } \\
\text { декодуванні, дБ }\end{array}$ & $\begin{array}{c}\text { Відношення } \\
\text { сигнал/шум при } \\
\text { адаптивному } \\
\text { декодуванні, дБ }\end{array}$ & $\begin{array}{c}\text { Енергетичний } \\
\text { виграш від } \\
\text { кодування, дБ }\end{array}$ \\
\hline \multirow{3}{*}{$(4,1,8,15)$} & $10^{-2}$ & 5,6 & 11,5 & 5,9 \\
\hline & $10^{-3}$ & 8,5 & 14,3 & 5,8 \\
\hline & $10^{-4}$ & 10,2 & 16,7 & 6,5 \\
\hline \multirow{3}{*}{$(5,1,16,31)$} & $10^{-2}$ & 4,3 & 8,9 & 4,6 \\
\hline & $10^{-3}$ & 6,9 & 12,4 & 5,5 \\
\hline & $10^{-4}$ & 9 & 15,2 & 6,2 \\
\hline \multirow{2}{*}{$(6,1,32,63)$} & $10^{-2}$ & 4,8 & 8,9 & 4,1 \\
\hline & $10^{-3}$ & 7 & 11,6 & 4,6 \\
\hline
\end{tabular}


3 аналізу отриманих результатів, поданих у табл. 1, випливає, що для заданих значень коефіцієнта помилок та обраних алгебраїчних згорткових кодів перемежування енергетичний виграш від кодування при застосуванні адаптивного методу декодування у порівнянні 3 алгебраїчним методом декодування складає від 4,1 до 6,5 дБ. При цьому зменшення швидкості кодування та збільшення глибини перемежування призводить до зниження енергетичної ефективності від кодування при використанні адаптивного методу декодування. Також з отриманих результатів випливає, що у заданому діапазоні відношення сигнал/шум адаптивний метод декодування у порівнянні 3 алгебраїчним методом забезпечує в середньому енергетичний виграш від кодування близько 5,5 дБ.

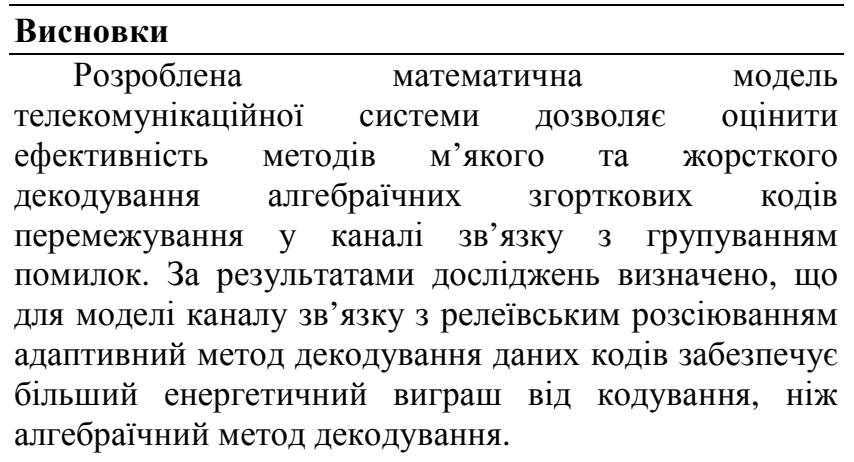

\section{Список використаних джерел}

1. Gluesing-Luerssen, H. On cyclic convolutional codes / H. Gluesing-Luerssen, W. Schmale Acta Applicandae Mathematica. 2004. Vol. 82, Issue 2. P. 183-237.

2. Gluesing-Luerssen, H. On doubly-cyclic convolutional codes / $\mathrm{H}$. Gluesing-Luerssen, W. Schmale Applicable Algebra in Engineering, Communication and Computing. 2006. Vol. 17, Issue 2. P. 151-170.

3. Приходько С. И., Кузнецов А. А., Гусев С. А., Кужель И.Е. Алгебраическое построение несистематических сверточных кодов. Cuстемь обработки информации. 2004. Вып. 8(69). С. 170 175.

4. Боцул А. В., Волков А. С., Приходько С. И., Штомпель Н. А. Метод построения алгебраических сверточных кодов перемежения 3б. наук. прачь Укр. держ. акад. залізнич. трансп. Харків : УкрДАЗТ, 2013. № 136. С. 232-235.

5. Боцул А. В., Волков А. С., Приходько С. И., Штомпель Н. А. Метод построения алгебраических несистематических сверточных кодов перемежения с произвольной скоростью кодирования. Інформаційно-керуючі системи на залізничному транспорті. 2014. № 2 (105). С. 8-11.

6. Боцул А. В., Волков А. С., Приходько С. И., Штомпель Н. А. Метод декодирования алгебраических сверточных кодов перемежения. Системь обработки информации. 2012. Вып. 7(105). С. 172 - 176.

7. Штомпель Н. А. Адаптивное декодирование алгебраических сверточных кодов перемежения. Інформачійно-керуючі системи на залізничному mранспорті. 2016. № 6 (121). С. $18-22$.

8. Приходько С. І., Штомпель М. А. Сєвєрінов О. В., Власов А. В. Принципи програмної реалізації адаптивного методу декодування алгебраїчних згорткових кодів перемежування. Інформаційнокеруючі системи на залізничному транспорті. 2019. Вип. 3. С. $25-30$.

9. Price K., Storn R. M., Lampinen J. A. Differential evolution: A practical approach to global optimization. Berlin: Springer-Verlag, 2005. 539 p.

Приходько С. И., Штомпель Н. А., Жученко А. С., Лысечко В. П., Шувалова Ю. С. Исследование эффективности адаптивного метода декодирования алгебраических сверточных кодов перемежения.

Аннотация. Разработана математическая модель телекоммуникационной системы, позволяющая оценить эффективность методов декодирования алгебраических сверточных кодов перемежения в канале связи с группировкой ошибок. Представлена схема и назначение основных элементов данной математической модели, а также определены особенности ее программной реализации. Показано, что для модели канала связи с релеевским рассеянием адаптивный метод декодирования данных кодов обеспечивает больший энергетический выигрыш от кодирования, чем алгебраический метод декодирования.

Ключевые слова: сверточные коды, перемежение, адаптивное декодирование, телекоммуникационные системы.

Pryhodko S., Shtompel M., Zhuchenko O., Lysechko V., Shuvalova Y. Performance study of adaptive method of decoding algebraic interleaved convolutional codes.

Abstract. It is shown that algebraic interleaved convolutional codes are widely used in the construction of telecommunication systems. The mathematical model of telecommunication system has been developed to evaluate the performance of adaptive and algebraic decoding of these codes in the communication channel with faction of errors. The scheme and purpose of the basic elements of this mathematical model are presented. The developed model takes into account the features of the transmission of information using algebraic interleaved convolutional codes depending on the parameters of the selected code, characteristics of interference in the communication 
channel and other factors. The process of information processing in each element of the presented mathematical model of telecommunication system is considered. The settings for the software implementation of the developed model are given: code type, code parameters, signal/noise ratio, number of information messages, parameters of the adaptive decoding method. As a result of the conducted researches it is determined that for given values of error coefficient and selected algebraic interleaved convolutional codes the energy gain from encoding when applying adaptive decoding method in comparison with algebraic decoding method is from $4.1 \mathrm{~dB}$ to $6.5 \mathrm{~dB}$. However, reducing the encoding speed and increasing the depth of interleaving leads to a decrease in the energy efficiency of the encoding using the adaptive decoding method. It also follows from the obtained results that in the specified signal/noise ratio for the communication channel with Rayleigh scattering the adaptive decoding method compared to the algebraic method provides an average energy gain from encoding of about $5.5 \mathrm{~dB}$.

Keywords: convolutional codes, interleaving, adaptive decoding, telecommunication systems.

Надійшла 27.06.2019 p.

Приходько Сергій Іванович, доктор технічних наук, професор, проректор з науково-педагогічної роботи, Украӥнський державний університет залізничного транспорту, Харків, Україна. E-mail: prihodko@kart.edu.ua ORCID ID: https://orcid.org/00000001-6535-8351

Штомпель Микола Анатолійович, доктор технічних наук, дочент, доиент кафедри транспортного зв'язку, Украӥнський державний університет залізничного транспорту, Харків, Украӥна. E-mail: tz@kart.edu.иа. ORCID ID: https://orcid.org/0000-0003-3132-8335

Жученко Олександр Серхійович, кандидат технічних наук, доцент, дочент кафедри транспортного зв'язку Украӥнського державного університету залізничного транспорту, Харків, Украӥна. E-mail: tz@kart.edu.иа. https://orcid.org/0000-0003-3275-810X

Лисечко Володимир Петрович, канд.техн.наук, доцент, доцент кафедри «Транспортний зв'язок», Украӥнський державний університет залізничного транспорту, м.Харків, Україна. E-mail: lysechkov@ukr.net ORCID: http://orcid.org/0000-00021520-9515

Шувалова Юлія Сердї̈вна, кандидат фізикоматематичних наук, доцент, доцент кафедри вищої математики, Украйнський державний університет залізничного транспорту, м. Харків, Украӥна. E-таil: Shuvalova@kart.edu.ua ORCID ID:
Sergii Pryhodko, Vice-rector for scientific and pedagogical work of Ukrainian State University of Railway Transport, Doctor of Technical Sciences, professor, Kharkiv, Ukraine. E-mail: prihodko@kart.edu.ua ORCID ID: https://orcid.org/00000001-6535-8351

Mykola Shtompel, Doctor of sciences (engineering), Associate professor (docent), Associate professor, Department of transport communication, Ukrainian State University of Railway Transport, Kharkiv, Ukraine. Email: tz@kart.edu.ua. ORCID ID: https://orcid.org/00000003-3132-8335

Oleksandr Zhuchenko, Candidate of Sciences (Technology), Associate Professor (Docent), Associate Professor at the Department of Transport Communication, Ukrainian State University of Railway Transport, Kharkiv, Ukraine. E-mail: tz@kart.edu.ua. ORCID ID: https://orcid.org/0000-0003-3275-810X

Volodymyr Lysechko, PhD, Associate Professor, Department of Transport Communications, Ukrainian State University of Railway Transport, Kharkiv, Ukraine. E-mail: lysechkov@ukr.net $O R C I D$ : http://orcid.org/0000-0002-1520-9515

Yuliia Shuvalova, Candidate of sciences (physicomathematical), Associate professor (docent), Associate professor, Department of Higher Mathematics, Ukrainian State University of Railway Transport, Kharkiv, Ukraine. E-mail: Shuvalova@kart.edu.ua ORCID ID:

https://orcid.org/0000-0003-4838-769X 